\title{
Erratum to: New Trends in Optical Network Design and Modeling
}

\author{
Alexandros A. Stavdas \\ National Technical University of Athens, Greece
}

\section{Erratum to:}

\section{A.A. Stavdas (Ed.) \\ New Trends in Optical Network Design and Modeling DOI: $10.1007 / 978-0-387-35410-1$}

The book was inadvertently published with an incorrect name of the copyright holder. The name of the copyright holder for this book is: (c) IFIP International Federation for Information Processing. The book has been updated with the changes. 